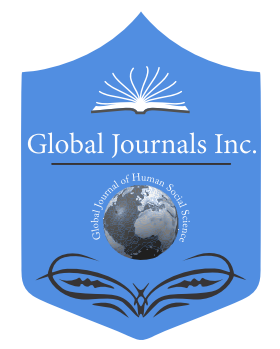

\title{
Exploring Social and Cultural Values in Contemporary Literature
}

By Dr. Alka Dutt

Amity University

Abstract- Paper aims to explore effect of society and cultural norms on minds of contemporary writers. Through literary writings students understand how world moves forward through interdependency. Writers writing in realistic stream try to touch upon facts and not on assumptions. They observe real life characters in a society set up and do not write what comes as historical truth. Complex behaviour can be seen in complex writings of contemporary writings. Man being a social animal loves to live life without adhering to age old traditions that gave strength to inner make up of one's character. Literature reflects negative and positive side of modern man. What is dealt with in Social Sciences, the same is pored out in words by poets, dramatists and novelists. Non literary writers like Jared Diamond emphasize upon effect of land topography on man's thinking process and not history or society that is all around him. Contemporary world is full of hardships. Examples from literary texts can support one to deal with these hardships. Examples would be taken from works written after World War 11 that fall under contemporary literature.

GJHSS-C Classification: FOR Code: 370199, 200299

Strictly as per the compliance and regulations of:

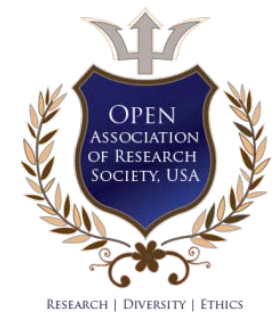

(C) 2020. Dr. Alka Dutt. This is a research/review paper, distributed under the terms of the Creative Commons AttributionNoncommercial 3.0 Unported License http://creativecommons.org/licenses/by-nc/3.0/), permitting all non-commercial use, distribution, and reproduction in any medium, provided the original work is properly cited. 


\title{
Exploring Social and Cultural Values in Contemporary Literature
}

\author{
Dr. Alka Dutt
}

\begin{abstract}
Paper aims to explore effect of society and cultural norms on minds of contemporary writers. Through literary writings students understand how world moves forward through interdependency. Writers writing in realistic stream try to touch upon facts and not on assumptions. They observe real life characters in a society set up and do not write what comes as historical truth. Complex behaviour can be seen in complex writings of contemporary writings. Man being a social animal loves to live life without adhering to age old traditions that gave strength to inner make up of one's character. Literature reflects negative and positive side of modern man. What is dealt with in Social Sciences, the same is pored out in words by poets, dramatists and novelists. Non literary writers like Jared Diamond emphasize upon effect of land topography on man's thinking process and not history or society that is all around him. Contemporary world is full of hardships. Examples from literary texts can support one to deal with these hardships. Examples would be taken from works written after World War 11 that fall under contemporary literature. Couple of books would be touched upon under the lens of socioeconomic, socio-political and socio-religious aspects as values take shape from all that a person undergoes and all that is around him and these are just few things that affect a personality.
\end{abstract}

\section{INTRODUCTION}

sen ndividuals crave for love and affection. They yearn for sense of belonging. This is not only human yearning, all living things move towards those who accept them as their own. Children grow up in a healthy manner when surrounded by loving family members. Simple living does not call for materialistic things to make life worthy and fulsome. Today lot of research is going on to balance modern lifestyle of people with emotional upheavals that crop up due to it. According to Audrey Osler, Social Science helps people in understanding what new technology can do for them. Negativity of technology can be best understood and dealt with proper knowledge that comes out as effort of social scientists from all streams of studies.

While subjects under Humanities and Social Sciences are almost same, slight difference makes sense as to what these two streams deal with. While Humanities take up critical approach and analytical approach, Social Sciences come with scientific approach in the subjects. There is more of philosophy in Humanities. Promoters of liberal arts in ancient Greece

Author: Assistant Professor, Amity University, Manesar, Gurugram, Haryana. Conference paper presented at SMVDU, Katra, Jammu.

e-mail: alkaduttdutt@yahoo.co.in promoted rhetoric, logic, music, geometry, astronomy, grammar and arithmetic. While these subjects were practically used in earlier times, rigorous study of them came up later. Social Sciences deal more with anthropology, administration, education, criminology, psychology, archaeology, linguistics, law, political science and economics. People like Karl Mark and Emily Durkheim popularised Social Sciences. French influence and the great Industrial Revolution directly influenced Social Sciences. Collective social improvement of society in general became major concern of Social Scientists. While humanitarians ponder us to think about major problems that assail society, Social Scientists give solution to resolve these problems. Subjects in Humanity make us move towards our tradition and culture and Social Science makes us live with whatever is present during one's life time.

Charles Dickens was not only a great writer of Victorian society, but also a social critic. His keen understanding of new inventions, changes in society due to advancement in technology was a start of understanding what today is termed as social ecology. Andrew Sanders says:

The more placid rhythms of rural life elude him as much as does an ability to observe and record the delicacies of a flower or the contours of a working landscape. Although he readily recognised the Romantic conventions of seeing nature as the inspirer and the regenerator, few of Nature's voices echo directly in his novels. As a writer of fiction, Dickens generally remained distinctly unawed by its phenomena.

Dickens writings can be viewed as works that cry out for a better world amidst chaos of new scientific inventions. Coming up of industries had created a dismal world as is very much apparent through novels of this great writer. Today advancement in every field of science be it nanotechnology or medical, is impacting life of man. Role of social scientists is crucial in helping man make the right choice in shaping a future for himself.

Lot of work is being done by interdisciplinary teams of social scientists to promote human welfare. They try to find out all that hinders social advancement and economic advancement. These scientists look out for a way to balance modern lifestyle by being actively in touch with social service agencies, funding agencies, government institutions and UN organizations. They influence economists, strategists, teachers, programme 
officers, planners and media among many others with their analysis of all that is causing hurdles to human happiness.

\section{il. Dystopian World of Huxley}

On one hand we have social scientists that are identifying problems that endanger well being of man; on the other we have writers commenting upon all that exists that is psychologically hazardous for future societies. Aldous Leonard Huxley, English writer of $20^{\text {th }}$ $\mathrm{C}$, a humanist and philosopher, came up with his great work, Brave New World. The novel explores how technology dehumanizes. Society reflected by the writer is futuristic society that eliminates natural birth of babies. Here babies grow in bottles through genetic engineering. Today man is by choice a person who is materialistic; but society of Brave New World is programmed to be one through biological manipulation and psychological conditioning, here there is no old age, disease, poverty, war or unhappiness. Free will of man is put down by sinister runners of World State. Here new technology is a tool to generate happy state of mind by taking away all natural emotions that are nectar of life. According to the ruler of this new world, Mustapha, "you can't make tragedies without social instability. The world's stable now. People are happy; they get what they want, and they never want what they can't get." While Social Science is finding out way and means to raise children in a happy and contented society where learning is more effective and where each child gets to express his views to his parents and mentors, children of Brave New World are conditioned to "love all" without any natural emotions. Creator of this world has not role to play in this scientific world, as he is not required to deal with any revolutions, unhappiness, old age problems, and other problems that occur time to time in a natural world. Huxley's book shows modern man who is undergoing crisis of lost individual identity of this fast-paced world. While Social Science explores world of finance to come up with solutions to unstable economy at individual level, citizens of Huxley's novel just need to work and be productive, shop, travel and spend money to be happy. Writer of Das Kapital (1867), Karl Marx, would have been horrified at this new method of production. Mustafa say that passive man will only feel "Universal happiness" and exposing man to inspired questions like as to "Why he exists?" would only lead him to become restless and useless for World State.

\section{UtOPIAN Thinking}

After World War 11 many new themes were taken up by writers. Island by Aldous Huxley came out in 1962. This Utopian Science fiction differs from dystopian Brave New World in its approach. High tech reproduction of Brave New World is substituted by artificial insemination that comes up as low-tech assisted reproduction. Utopian society of Island adapts and blends western science with its own culture to promote the society. Social Scientists dealing with Bio cultural Anthropology research on biology of humans and culture that affects them. Society of Island is different from that of Brave New World. People are intellectual and spiritual. They suffer and feel pain. Society of Brave New World is not allowed to feel normal human emotions that enrich one's life. Drugs by the society are used not to work like men put under trance, but to achieve higher goals in learning that are nearer to superior knowledge. Restrained industrialization around the place allows time for leisure and progressive contemplation. Unlike materialistic technology of earlier novel, technology in the latter is used in a selective and positive manner. People know what religion is and what God stands for. Here there is no Mustafa but Mahayana Buddhists to lead towards better living. People of Brave New World are guided by mechanical voices but those of Island by trained Mynah birds. This reminds one of George Orwell's novel, 1984, where minds of people are terrorized and captured with aid of modern technology. Technology by Palanese of Island is used to benefit society. Hydroelectricity by them is not rejected as promotional tool of industrialization. They make use of it to store surplus for fresh food items. This in turn gives boost to good nutritional diet and also lessens the fear of food shortage. Social geographers from University of Sheffield, emphasize upon good eating habits that would make them healthy and fit enough to cope up with old age. Sports sociologists too advice good diet plan as sports are strenuous. Today nanotechnology is a boon to food industry as conventional packaging is replaced and this allows for long life of packed food. It allows consumer to identify contaminated food items. Research has revealed that people have been eating food with nanoscale components for generations. More varieties of food offering improvised taste and texture are coming up for consumers. Food industry is revolutionized with each new finding of Nanotechnology.

Workings of mind can be traced through Social Sciences. Criminology and psychology can be seen at work in above mentioned works. According to Julie Harrower's Applying Psychology to Crime, "Criminology attempts to integrate the potential contributions of a wide range of disciplines in order to study criminal behaviour and legal issues." Literary minds have been attempting for ages to know what preoccupies the mind of a murderer. Retreat into the Mind: Victorian Poetry and the Rise of Psychiatry by Ekbert Faas talks about the issue in great detail. According to him, "murder, or the attempt at it, is the second most stereotypical event found in the history English Literature." Shakespearean plays can be explored for psychological murderers. De Quincey supports this attempt as he says a murderer's mind should be psychologically probed and analysed. 
His essay "On the knocking at the Gate in Macbeth" (1823) is worth reading as it also comes with a casestudy. Psycho by Robert Bloch is fictional novel that comes with horrific tale. Bates, the protagonist, is identified with dissociative identity disorder as he victimizes clients to his motel under the guise of his own mother. The man had undergone a terrible phase of life. His father had deserted him and the mother at an early age. Total co dependence (psychological) state of mother and son lead to abnormal lifestyle. Son kills mother and her lover and then continues to commit other murders. Such works prove interrelated relationship of criminology to literature. Both disciplines come up with human emotions, personality and motives of a person. Literature has in fact gone on to influence Criminal Theories. Students studying Criminology are exposed to fiction that clarifies many criminal theories. Brian Masters wrote a novel on a real-life necrophiliac, Dennis Nilsen (1945-2018), Killing for Company. The writer compares Nilsen to a character found in Dostoyevsky's Crime and Punishment. Such works go on to show how literature influences theories in Criminology. Robert Browning's "Porphyria's Lover" (1836) was based on a true life incident. The story had come up in Blackwood Magazine based on John Wilson's narration.

\section{Conclusion}

Interdisciplinary study allows students to be addressed in a profitable manner. This approach to learning allows enhancement in knowledge as students of literature get to know about other disciplines, cultural methods of critique and ideologies. Synthesis of different ideas takes place and promotes critical thinking. New understanding is reached when multidisciplinary approach is taken up by educational institutions. Here normal study boundaries are crossed over to pave way for new paths. Best out of other subjects is combined with subject in hand. As human beings, we are all in some manner interdisciplinary and multidisciplinary. Universal patterns can be identified through all fields of study by passionate readers that in turn lead to good comprehension of the text.

\section{References Références Referencias}

1. Alshiban, Saleh, Afra. Exploring Criminology in Literary Texts: Robert Browning - an Example. Jordan Journal of Modern Language and Literature, Vol. 5, No. 1, 2013, pp. 55-70. (Nom4.pdf)

2. Dickens in the City: Science, Technology, Ecology in the Novels of Charles Dickens. https://www. researchgate.net. April 2010.

3. Difference Between Humanities and Social Sciences. Difference Between.net. http://www. Differencebetween.net.
4. Huxley Aldous. Brave New World. https://archive. org.

5. Nilsen Dennis. https://en.m.wikipedia.org. 